\title{
NGOS: THE CASE OF RDRS IN BANGLADESH
}

\section{Andy Batkin}

\section{INTRODUCTION: NGOS IN BANGLADESH'}

NGOs are now actors in the development process in Bangladesh on a scale unmatched in other developing countries. Aid flows following the 1971 War of Independence and recurrent natural disasters, and a relatively liberal legal framework, have enabled the growth both of international NGOs and national agencies led by risionary Bangladeshis schooled in the Independence Movement.

By early 1992, almost 600 NGOs were registered under the 1978 Foreign Donations Ordinance of which 20 per cent were International NGOs (Government of Bangladesh 1992). Official bilateral donors are increasingly finding channels to use NGOs in project implementation and many multilateral-supported projects now include a sizeable NGO component. With encouragement from official donors (who fund over 80 per cent of the country's development budget) the Bangladesh Government is increasingly coming to accept the NGO role. ${ }^{2}$

The growing size and prominence of NGOs in Bangladesh has generated increased demands for scrutiny from Government and donors. The emphasis of donor evaluations is on inputs, outputs, and financial control whilst Government-sponsored research has concentrated on relative cost-effectiveness. The internal organization, structure and function of NGOs is still largely unstudied and the potential lessons for development administration under-explored. This article examines the organizational characteristics of one of the International NGOs, the Rangpur Dinajpur Rural Service (RDRS) in an attempt to understand how it works and how it achieves what it does.

\section{THE RANGPUR DINAJPUR RURAL SERVICE}

RDRS is one of the largest NGOs in Bangladesh. It is the fourth largest in terms of staff numbers (with just under 1,700 staff by mid-1992) and the fifth largest in terms of programme expenditure. A notable dissimilarity from other large NGOs is RDRS's regional

1 The author is grateful to staff throughout RDRS for the many insights which contributed to this article.

2 By 1992, the Government's stated position on NGOs was as follows: 'NGOs have gradually emerged as active partners in development in Bangladesh .... as the government efforts have always been in need of being further supplemented . . . There should be continuous GO- concentration. The RDRS working area embraces 28 contiguous sub-districts in the poorest North West part of the country, with a population of almost 6 million people.

Like several of the large NGOs, RDRS was born out of the War of Independence, and its work has progressed from refugee and relief assistance, through post-War rehabilitation, to encompass a wide variety of development interventions. In 1988/89, RDRS underwent a major reorganization into two integrated Projects. The larger Comprehensive Project took responsibility for group-based motivation and training work on literacy, women's development, agricultural extension, income generation, and primary health, and the Rural Works Project for water-management, infrastructural development and forestry. New policy papers for both projects were prepared, and common activity monitoring introduced. A personnel system and an independent structure for financial control were established. Six sectoral Advisory Units were created to provide technical support and co-ordination for the whole programme.

By early 1992, the field programme was staffed entirely by Bangladeshi nationals. Four expatriate staff are based in the Dhaka office working mainly on relations with donors and government.

\section{RDRS: THE EXTERNAL ENVIRONMENT}

\section{Donor relationships}

RDRS's formal parent is the Geneva-based Lutheran World Service (LWS), which funds 25 country programmes, mostly in Africa. LWS is a multilateral funding agency, drawing financial support principally from North European and North American NGOs (the Related Agencies) which are supported by voluntary donations and from their respective nation's official development aid budgets.

RDRS differs from other LWS country programmes in that it is both the largest and most developmentoriented, with no main-programme relief or refugee activities. Despite their Lutheran roots, RDRS's

NGO dialogue which would remove mutual distrust ... The Fourth Five Year Plan provides mechanisms for integrating NGO programmes with the local level planning . . ' Government of Bangladesh 1992:79-81). The creation of the NGO Affairs Bureau in 1990, now part of the Prime Minister's Secretariat, has centralized and improved official communication and relationships with NGOs. 
Related Agencies have been supportive of RDRS positioning itself as a professional development agency with no religious overtones. The Related Agencies, through LWS, now provide about two thirds of RDRS's funding requirements.

Until the late 1980s, RDRS's relationships with LWS and the Related Agencies were based mainly on trust. LWS reporting requirements were very mild and field programmes were under little pressure to systematize planning, monitoring or reporting. Questions on development strategy, impact or cost-effectiveness were rarely asked. An audited set of accounts and an Annual Report were sufficient, supplemented by nonspecialist review missions every three or four years. LWS Field Directors were assumed to be spending money appropriately and had great freedom in terms of field activities.

In the past five years there has been a transition from looser trust-based relationships to more formalized systems. This resulted mainly from pressure from the official aid agencies, themselves facing increasing demands to display accountability for government expenditure. Consequent pressure on LWS from the Related Agencies led to the introduction of the LWS 'Planning and Monitoring System' in 1987, requiring five-year plans, budgets and progress indicators for all LW S Country Programme Projects. Professionalization of RDRS's strategy formulation, planning and reporting systems further developed during 1991 as a result of growing involvement in Bangladesh Government donor-aided projects. Imposed planning requirements help extend time horizons and prompt greater attention to strategy formulation.

In relation to new funding sources, NGOs work in a quasi-market. They cannot tax or borrow to fund their activities and they cannot deploy the institutional pressure on donors to ensure the aid finance that is available to civil servants. The limited funding capacity of the Related Agencies is increasingly leading RDRS to become a competitor for participation in donoraided Government Projects.

Both the stronger regulatory regime imposed by donors, and the need for sharper project formulation to win funds in a competitive situation have been helpful in prompting improvements in RDRS's planning, performance measurement, and reporting systems.

Several Bangladesh NGOs, including RDRS, now have multi-million dollar turnovers. Their long-term future depends above all on finding effective structures of ownership and control. Despite the growth of more formalized donor relations, RDRS still has a high degree of freedom vis-à-vis LWS Geneva, and operational accountability is loose.
Although RDRS is formally accountable to the Government of Bangladesh through the NGO Affairs Bureau, the need for a better structure of accountability rooted in Bangladesh has become increasingly apparent. Other International NGOs have established a Bangladeshi Society, made the organization accountable to the Board, and re-registered as a National NGO. RDRS is now investigating several such options, with the aim of clarifying ownership and control and increasing accountability to Bangladesh and donors.

\section{Beneficiary relationships}

RDRS's Comprehensive Project works with 120,000 hou seholds who are either wholly landless or own up to one acre of land. Land ownership is increasingly concentrated in the hands of medium and large farmers, and 70 per cent of the one million households in the RDRS working area now fall within the RDRS target group definition. Half the Comprehensive Project groups and households are female. Needs are immense, with over half the families in the RDRS working area living in chronic poverty. Unemployment and under-employment are endemic. Illiteracy is around 80 per cent. Government services barely reach the poor.

The majority of RDRS staff are from the working area. Many of the grassroots organizers are themselves part of the poor, living in bamboo and thatch huts in villages without electricity or proper roads. RDRS staff are often the main income earners in their families and share their salaries amongst poorer relations. Many staff continue to farm family plots of land in the working area.

RDRS carries out surveys to assess beneficiary needs and perceptions. In November 1991, for example, all RDRS field executives spent two days, in groups of three, asking randomly selected Comprehensive Project group members about their views and priorities.

The activities included under the Comprehensive Project fall into two groups. First are those which directly address the needs expressed by people themselves. These are mainly in the income generation field: training on irrigation, crops and livestock, credit for rice-processing and rickshaws, etc.

The aim of the second group of activities - group organization and joint savings, latrine use, child immunization, family planning, intra-familial responsibilities and the role of women, for example - is to inculcate understanding about why certain practices are desirable, whether or not these are directly articulated as felt needs by people themselves. Ideally 
the development process should be one of progressive awareness building and enabling. However in an environment of hierarchic and autocratic social relations, this can easily become a process of coercion and instrumental behaviour. The desire of field staff to demonstrate achievement to superiors, and the desire of beneficiaries to maintain good relations with NGO field staff can distort relationships. For example, group members will build a latrine with the aim of satisfying the RDRS Organizer, with little real belief in its importance in diarrhoeal prevention, and no serious intention of using it.

Many field staff do succeed in building genuinely participatory and enabling relationships with beneficiaries. It is difficult to identify common characteristics amongst such staff, but similar social background, living close to the beneficiaries, and an ideological empathy with the poor appear to be important factors. It is normally easier for female staff to establish empathetic relationships with female beneficiaries, which is why RDRS female organizers work mainly with women's groups.

Some Bangladesh NGOs deliberately exploit the authoritarian tendencies of the culture and the desire to satisfy superiors, using quasi-military rituals and slogan-repetition to reinforce development messages. RDRS uses a lower key approach, but the danger of overly heavy-handed motivation is always present. Building authentic knowledge, attitude and practice is not easy.

As the largest and best-known NGO in its working area, RDRS interventions benefit greatly from the trust relationship built up with local people over the past 21 years. This relationship also carries dangers. Patron-client relationships are the determining feature of the rural power structure (e.g. Maloney 1988; Jansen 1987) and NGOs always run the risk of becoming the 'new patrons' and breeding new dependencies amongst the poor. With insecurity widespread, involvement with a large NGO is itself a prized asset. The more effective the NGO, the greater the risk of dependency. RDRS aims to phase-out intensive contact with groups within four to five years, so that new people can be brought into the project. Finding strategies to ensure that beneficiary relationships foster a real self-reliance consciousness rather than a new clientism continues to be the single most difficult task in rural development in Bangladesh.

\footnotetext{
${ }^{3}$ Few NGOs in Bangladesh are involved in infrastructural improvement. In the RDRS working area it has been of importance in poverty alleviation, a judgement which is supported by the results of Ahmed and Hossain's recent study. They compared different villages in Bangladesh which were well or poorly served by various infrastructures, and found that where there was good communication between centres, villagers had access to cheaper agricultural inputs, higher paying jobs, health facilities and markets for their produce. They concluded that good infrastructure caused household income
}

In terms of working method, most Bangladesh NGOs choose not to work through traditional community institutions, considering them too subservient to élite interests. Substantial staff resources are therefore required to create new informal groups and larger community organizations as a vehicle for development activities. The Comprehensive Project has 1,300 field and support staff and 600 paid volunteers. Half the field level Organizers are female and almost all of them work solely with groups of women. No free inputs are provided to clients apart from literacy materials and a modest credit fund.

The RDRS Rural Works Project's communications, drainage and public infrastructure work complements the Comprehensive Project's group-based work. ${ }^{3}$ The Project works in partnership with local government, enabling it to be more economical on staff, providing mainly structure design, site supervision, logistics, materials and labour payments.

\section{Relationships with government}

All RDRS activities are either directly approved by the Government's NGO Affairs Bureau or are part of donor-supported Government projects. At field level, RDRS activities entail one of five modes of relationship with government. Most activities combine more than one at a time.

RDRS operates as a supplement to government: doing things which government does not or cannot do. For example, government agriculture extension services concentrate on medium and large farmers. RDRS's emphasis is on homestead systems, livestock, irrigation and minor crops with the landless and marginal farmers.

RDRS also operates as a substitute: doing things which the government should be doing but does not have the resources or capability to complete. School construction and running non-formal primary schools substitute for direct government provision in meeting its objective of universal primary education.

RDRS works as an operational partner to government: in running satellite antenatal services in government health centres; in constructing small bridges and culverts on rural feeder roads; in motivating women to bring their children for immunization; in offering education and social-awareness training to poor women under the Government's 'Vulnerable Group Development' scheme.

to rise by 33 per cent, income from agriculture by 24 per cent, from livestock and fishing by 78 per cent, while wages almost doubled. The functionally landless and small farmers gained a greater share of the increases from crops, wages and livestock and fisheries, while the larger landowners captured most of the increases in income from business and industries (which rose by only 17 per cent). On this evidence, confirmed by RDRS experience, rural infrastructure is distributionally progressive. 
Adult conscientization, women's organization, confidence-building and legal rights training are civilsociety building interventions it is difficult for the state to adopt directly. Although governments will always be ambivalent about the role of NGOs in helping people vocalize their own demands on the state, its importance - particularly in the context of recent democracies - is difficult to deny.

Last, and perhaps most important, RDRS is often seen as a model for government. Local politicians and government officers frequently point to RDRS as capable of performing activities effectively and efficiently.

Some NGOs in Bangladesh are increasingly positioning themselves, with donor support, as alternative 'development corporations'. Objectives of eventual hand-over to government are being abandoned. RDRS continues to see government as the primary agency of development with the rural poor in the long term, and indirect capacity-building assistance and 'modelcreation' remains an RDRS goal.

\section{INSIDE RDRS}

\section{Goal formation}

Before 1988, RDRS was, in effect, a federation of projects. Strong sectoral projects grew up in agricultural extension, rural construction and barefoot health services, mainly under expatriate staff. Bangladeshi executives began education and motivation programmes with the landless on the Freire model. With no common programme policy, working area, client group, or activity monitoring, the CEO's task was mainly one of enabling each component of the federation rather than stamping central goals and consistency on the organization. Following external pressure for greater goal clarity, compounded by internal inconsistencies, two pilot Comprehensive Project Units were established in 1986, culminating in the $1988 / 89$ reorganization into two integrated Projects.

To what extent did this reorganization help to clarify RDRS's development goals? On the one hand it achieved a unified policy understanding within RDRS, based on the new bilingual Policy Papers (RDRS 1989a; RDRS 1989b) which defined common goals and

\footnotetext{
4 Israel's conclusion from his review of institutional success and failure was that projects with more modest and narrowly-defined objectives were more likely to succeed. Israel's 'sin of comprehensiveness' is the tendency of project planners to create over-ambitious, multicomponent designs which require complex project structures and generate territorial disputes, intractable inter-institutional conflict and implementation delays. RDRS's Comprehensive Project has tended to run into similar problems, albeit within a single organization. When needs are so great, the problems so
}

activities for each Project. However objectives were still insufficiently specified. The second recommendation made by the 1991 RDRS Review Mission was that 'the objectives of RDRS be clarified and refined in relation to its actual activities, and policies and projects be adjusted accordingly' (Palmer-Jones et al 1991).

The 1988/89 reorganization had thrown together all the activities of the disparate sectoral projects, and RDRS goals had come to embrace the gamut of possible NGO functions, from empowerment to public service contracting. In its drive for holistic coverage, the Comprehensive Project in particular had come too close to committing what Arturo Israel has called 'the sin of comprehensiveness' (Israel 1987: 199). ${ }^{4} \mathrm{~A}$ further clarification of objectives began in late 1991, including studies of beneficiary opinions, internal staff discussions, a strategic planning workshop on the Comprehensive Project and a senior staff retreat.

The strength of RDRS's goal formation process has thus been its grounding in field experience and beneficiary needs. That very process has also generated RDRS's main weakness in goal for mation: hoping to do too much with too many people at once. Ambitious holistic aims have predominated, as against the need for selectivity in attuning goals to available skills and time resources.

\section{Structure, functional allgnments and role relatlonships}

Max Weber would have approved of the RDRS organizational structure. RDRS is a hierarchy with clear lines of accountability from one level to the next. All staff have designations, written job descriptions and a locus in the RDRS organogram. The Comprehensive Project's eight Units and the Rural Works Project's three Units cover the whole working area. Each Unit is managed by a Project Administrator. There are six steps of hierarchy between the Chief Executive and grass roots staff. Separate divisions control financial and activity monitoring. The basis of legitimate authority is clear to all.

The main ambiguity in the RDRS structure occurs with the Advisory Units, particularly those concerned with the Comprehensive Project: Agriculture, Education, Health, Off-farm Employment Generation and

interconnected, and the aspirations of the organization so high, the danger is to try to do it all. RDRS is now in the process of defining sharper sub-objectives and delivery systems that are easier to plan, implement and monitor. Instead of trying to offer a wide variety of interventions to 120,000 households, providing livestock improvement or legal rights training to selected women's groups, for example, may prove to be managerially simpler and achieve higher quality results with a stronger and more sustainable demonstration effect. 
Women's Development. The Advisory Units have a 'dotted line' relationship with the technical specialists for each discipline in each Comprehensive Project Unit. Thus the Agriculture Officer in Kurigram Comprehensive Project Unit, for example, is formally responsible to her Project Administrator, but is also in regular contact with the Agriculture Advisor.

As with all matrix structures, the Advisory Unit arrangement has met with mixed success. The alternative of bringing the technical specialists in each Project Unit directly under the supervision of the appropriate Advisor, and thus introducing more sharply-defined sectoral programmes is under consideration.

The RDRS structure reflects both the pervasive hierarchical ordering of social relations in Bangladesh and the colonial administrative heritage. Using India and Pakistan as proxies, Bangladesh should appear as a 'Large Power-Distance' society within Hofstede's cultural typology (Hofstede 1980) and attitudes to power relations in RDRS tend to bear this out. Superiors expect to receive 'due honour' and subordinates expect to give it.

In practice, of course, role relationships are not fully determined by structure. An increasingly participatory culture operates within the formal structure. Very rarely are decisions taken by senior management without obtaining a 'field view' first. Within each Project Unit, the Project Administrator and his senior staff work closely together. There is also evidence that RDRS staff enjoy working in 'Task Tribes' (Handy 1990:150 et seq.), outside officially-defined role relationships. RDRS's short-term rehabilitation project, after the April 1991 cyclone in the south, was implemented by three multi-disciplinary teams posted in different sub-districts. Interviewed at the end of their five-month spell of work, all three teams expressed strong support for more unstructured and task-centred relations: 'There were no grades or designations. The health worker was supervising housing construction; the engineer was doing health education' (see 'Participant Evaluation' in RDRS 1991). Task-tribe organization appears to be of general appeal, ${ }^{5}$ and some RDRS Managers adopt team approaches through personal inclination.

Less hierarchic attitudes throughout RDRS would be beneficial, but judged in terms of output achieved, the present structure seems to work relatively well. To

\footnotetext{
5 A recent study of attitudes to organizational culture amongst staff from a wide range of developing countries found that over 80 per cent would prefer a task-tribe culture, even though they expected to spend the rest of their lives in role-deterr ined structures (Franks 1989).
}

6 During 1992 all RDRS Executive Staff are being trained in the what extent a Tas-tribe approach would be generalizable as an organizational principle is not clear.

\section{Planning}

Formal project planning in RDRS has traditionally been weak, mainly as a result of the limited planning and reporting requirements imposed by donors. The 'loose-tight' balance achieved after the 1988/89 reorganization has been generally successful. Common programme policies, activity monitoring, personnel and financial control have enabled improvements in performance measurement and reporting, whilst leaving operational planning and targeting decentralized.

Project Units have broad freedom to plan priorities according to local needs. The Units are also free to experiment with different working methods. For example, some Comprehensive Project Units use intensive small group methods only. Others use federations of groups and mass meetings of up to 20,000 people. During 1992, all senior staff are being trained in Participatory Project Planning to help strengthen technical planning skills, whilst maintaining sensitivity to the needs and capacities of beneficiaries and other institutions. ${ }^{6}$

What are the lessons from RDRS for the Process/Blueprint debate originating in Korten, 1980? The simplest characterization of the RDRS experience would be 'A Procession of Blueprints'. The 1989 Policy Papers synthesized 15 years experience from the former sectoral projects. They also contained the anomalies necessitating revision.

One of RDRS's most distinctive characteristics is its growing capacity for self-assessment and change. More rigorous planning and impact measurement are the essential inputs to this process whilst a more participatory culture lubricates trading of criticism and ideas. The policy revision process which began again in RDRS in mid-1991, less than three years after the previous round, will generate new blueprints, albeit with a life-expectancy little longer than their predecessors.

\section{Co-ordination and communication}

Vertical communication within RDRS follows the pattern established by the organizational structure. Top-down communication tends to be formal, and bottom-up, informal. A bi-monthly newsletter (in Bangla) provides an additional channel for news dissemination throughout the organization.

Goal-Oriented Project Planning methodology now used worldwide by the German Development Agency GTZ. The methodology involves problem analysis, objective formation and logical framework-based operational planning conducted in a manner which enables involvement by beneficiaries and project participants. 
The Programme Co-ordinator, based in the geographical centre of the working area in Rangpur, is responsible for field activities and for co-ordinating the 11 Project Units. The Programme Co-ordinator chairs meetings of the Project Administrators on a six-weekly cycle and all Executive Staff meet every two months. The December Executive Staff meeting each year is spread over two or three days, and is the main forum for reviewing the year's work and future priorities. The six Advisory Units co-ordinate work within their own sectors and link RDRS into the work of government.

\section{Management control and accountability}

At the field level, the 11 Project Administrators are formally accountable for the work of their Project Units. In discussion, they feel accountable, and feel they have the necessary backing and resources to be so.

The pervasiveness of kinship and other non-Weberian linkages in developing countries have been widely discussed. From the perspective of senior RDRS executives, the single most-appreciated role of expatriates within RDRS over the years has been in providing a 'cultural cut-out', offering added protection from such pressures. The desire to preserve this freedom to manage leads Bangladeshi executives to express major reservations about the desirability of RDRS becoming a national NGO. 'How can I discipline a member of staff if he can go over my head to a relation on the board?' is a universally expressed concern.

Managing staff and resources in rural Bangladesh is a dangerous business. Competition for scarce resources creates a host of pressures including direct physical threats to home and family. Managers can only be held accountable, and be accountable, where they have backing from colleagues and superiors. Anxieties about the consequences of localization amongst senior staff may be over-stated, but they are real. ${ }^{7}$

The complementary, but less mentioned, management freedom which RDRS and other NGO managers in Bangladesh enjoy, is from organized labour. Throughout the state sector, unions are a powerful constraint on management due to their wide coverage and linkages into the political superstructure. Life is undoubtedly easier for NGO managers in the absence of licit and illicit pressures from organized labour.

There is something of a paradox between the organization and empowerment goals of many Bangladesh NGOs and the absence of countervailing power from organized labour in their own organizations. Senior staff in RDRS care about their staff and go to

\footnotetext{
7 Weber's first criterion for stalf in 'modern Western state' bureaucracies was that: "They are personally free and subject to authority only with respect to their impersonal official obligations.'
}

considerable lengths to support them. The culture is one of benevolent paternalism in the best sense of the term. Staff at all levels talk of the 'RDRS family'. The growth in more participatory attitudes has enabled individual and collective staff discontent to be aired more openly. However in the absence of formal mechanisms for staff representation in RDRS and other NGOs there is always a danger of organizational achievement resting too heavily on unconstrained exploitation of labour.

\section{Financial control}

Financial Control in RDRS is achieved in two ways. First, by systems developed over many years whereby all procurement and expenditures are subject to a panoply of regulations covering authorized expenditure limits, tender committees, stock control procedures, etc. The diversity of requisite authorizations means that misappropriation demands very extensive collusion. Periodic rotation in the posting of accountants, store-keepers and other key staff makes it difficult for such collusive relationships to develop. Roving internal auditors make unannounced spot checks, as do the bi-annual external audits conducted by a leading firm of chartered accountants.

The second contributor to financial control is that any member of staff who is found guilty of misappropriation is guilty of 'gross misconduct' under the personnel rules and is released from service. This rule is applied rigidly and irrespective of designation, length of service or past record. This is a long-standing feature of RDRS culture and organization. It is well-understood by all staff and has a powerful deterrent effect. Both RDRS management and its external auditors consider that RDRS is almost entirely corruption-free: in the past five years less than a dozen cases of wilful misappropriation have been detected.

\section{Performance and management information}

Hard indicators of performance in non-market organizations are difficult to obtain. Rural development organizations are faced with the task of defining indicators for objectives such as women's empowerment, functional literacy, and share-cropping rights; achieving consistency in the measurement systems; and then coming to judgements about achievement and progress rates.

The RDRS Rural Works Project is relatively easy to monitor. Rural infrastructures and tree plantations, even in remote places, are visible and countable. With good systems for material and financial control, the monitoring task is straightforward.

(Weber 1947). The 30 Bangladesh Executives in RDRS would agree with that view. 
Following the establishment of the Comprehensive Project in early 1989, a new monitoring system was developed with the aim of providing verifiable data which could be aggregated from the individual household up to the Project as a whole. 50 indicators were selected, covering the main Comprehensive Project interventions. A 'minimum requirements' definition was drafted for each indicator, followed by extensive consultation and field-testing. Each indicator was designed to measure effects rather than inputs. For example, the sanitation indicator defines and measures members of the household properly using a latrine rather than 'latrines constructed'.

The 650 Comprehensive Project Organizers are required to up-date their monitoring record every two months, with aggregate data being computed at subdistrict and Project Unit level. Despite the size of the monitoring system (120,000 households and 50 indicators) the task of data collection and aggregation is manageable since the aggregation process is decentralized and performed manually at successive levels. Data for the seven Comprehensive Project Units are compiled centrally (on a computer spreadsheet) by the five staff of the Rangpur M \& E Section. Tabulated reports from the Community Health Unit (leprosy treatment and satellite antenatal centres) and the Rural Works Project are added, and a summary of main points is drafted. This forms the Bi-Monthly RDRS Monitoring Report, covering all Project activities. The Report is normally available two weeks after the end of each two-month reporting period.

The Organizer's monitoring books are large-format and hard-bound in plastic covers. They are weatherproof and can be safely stored for years, to facilitate longitudinal research. The Monitoring Book is also designed to enable beneficiaries to see and record their own progress and help them in their own planning. A double page format in the book contains the progress record for each group of about 15 households for two years. This format offers a simple picture of areas of progress and possibility, accessible to the illiterate.

The Monitoring System was designed to fit in with the Project's staffing structure, enabling third-party checking for consistency. The sectoral specialists within each Project Unit check the accuracy of the monitoring during field visits. The bi-monthly monitoring system is complemented by small-sample internal evaluations, and bi-annual nutrition monitoring.

Achieving effectiveness in rural development is difficult; measuring it even more so. With a large field staff dispersed over a wide area it is all too easy for rural development organizations to quote whatever level of coverage and impact they choose. Performance control depends above all on the quality of the organization's internal $\mathrm{M} \& \mathrm{E}$ systems and their implementation in the field.

\section{Innovation}

The Project Administrators have freedom to test new activities and delivery systems within their Units. The six Advisory Units are also important sources of innovation. For example, intensified work on sericulture (silk production) grew out of exploratory work by the Employment Generation Advisory Unit, including a study of village silk production methods in Thailand. The Agriculture Advisory Unit continues to develop low cost irrigation technologies based on the treadle pump pioneered by RDRS in the early 1980 s (Orr et al 1991).

The Women's Advisory Unit is the driving force in continuing to strengthen gender strategies, including motivational materials, women's legal rights training, mass participation in International Women's Day, the Female Trainee Scheme, child-care support and policies for female staff. The impoverishment and exploitation of women in Bangladesh is widely recognized, and most poverty-focused development projects now target women directly. RDRS has made considerable progress in recent years both in increasing the number of women involved in programmes (group organization and development, maternal and childhealth, tree caretaking) and in innovating new interventions with women (training for adolescent girls, emphasis on male contraceptive acceptance, sericulture, village-based mechanized rice-hulling, village tailoring). One indicator of the impact of the Women's Advisory Unit and growing gender awareness is that several of these innovations have been piloted and developed by male staff.

\section{Staffing, skills and reward structure}

All RDRS Executive Staff are employed on two year contracts. Contracts for the four international staff are with LWS in Geneva, with pay-scales and increments according to designation. The RDRS Chief Executive meets national executive staff to review achievements over the previous two years, and pay increases are related to performance.

98 per cent of RDRS are graded by designation on a 10 grade salary matrix. All staff normally receive an annual increment (worth 7 per cent) provided their performance during the year has been satisfactory, plus whatever increase in the whole matrix is affordable within the fixed budget constraint (normally about 3-5 per cent). 20 per cent of graded staff also receive one month's basic pay as 'Merit Award'. Administrators and Advisors make this selection annually, usually in consultation with line managers and other senior staff in their Units. 
There is thus no strong performance-related pay system in RDRS. The difficulties of ensuring fairness and consistency in such systems in the non-market service sector are well-known, and are certainly beyond the capacity of RDRS to achieve at the present time.

In terms of salary level, RDRS aims to maintain parity with similar-sized NGOs. As a result of tight budget constraints, RDRS salaries have fallen behind in recent years, particularly for mid-level staff. For the first time salaries for graded RDRS staff are now lower than government rates. It is arguable that organizations like RDRS, which offer no job security guarantee and where there is no possibility of augmenting salaries illicitly, should pay a premium over government rates.

One manifestation of the complexity of RDRS objectives is the volume of staff training required. RDRS has three large residential training centres, each with a capacity of 50 , and several smaller centres. These are in continual use. The experience of trying to create multi-skilled field staff to Implement Comprehensive Project activities has been mixed. Bringing Organizers with School Certificate qualifications to the point where they are able to cover a large number of activities, however simple, has been very problematic. Imparting a large volume of technical skills may also have been at the expense of building deeper field staff knowledge, attitude and practice in concepts of selfreliant development. ${ }^{8}$

Female staff recruitment and development has been a major priority in recent years. RDRS is known as an effective developer of women staff, and poaching is a problem. The requirement that all female field staff must use bicycles or motor-cycles is nationally known, and has been a model for many other organizations. The Female Trainee Scheme, introduced in 1990 for women with good academic records but little field development experience, has been very successful in increasing the number of women in mid-level positions. Despite increasing gender consciousness in recent years, the 1991 Review Mission (Palmer Jones et al 1991) recommended a programme of gender awareness training for all staff, and this will be implemented over the coming year.

\section{Leadership and value systems}

Leadership theory is increasingly focusing on the role of the leaders in reinforcing an organization's value systems: 'Clarifying the value system and breathing life into it are the greatest contributions a leader can make' (Peters and Waterman 1982).
RDRS's leaders are its 35 Executive Staff. It's value systems are nowhere stated, but clear to all. Three values stand-out: personal integrity, personal commitment, and field orientation. Selection of executives, and the respect accorded to them within the organization, tends to be in line with this value system. These core values override academic excellence or seniority. For example, new Executive Staff with outstanding academic records can expect to spend years proving themselves to their colleagues. Deskwork, of whatever quality, generates less respect than being seen 'in the field'. A failure in strategic planning is likely to be less commented upon than a questionmark over a financial transaction involving 100 Taka.

\section{CONCLUSION}

The failure of Bangladesh to join the growth-path of other Asian nations, despite abundant development opportunities, is rightly seen as a failure of institutions. The central question in Israel's study of Institutional Development in World Bank Projects is 'Why is the performance of one institution better than that of another in a similar environment?' (Israel 1987:11). What are the organizational features of RDRS which enable it to be as comparably efficient and effective as it is judged to be (e.g. Palmer Jones et al 1991:5)?

Despite the difficulties of working in one of the world's ten poorest nations, RDRS does appear, albeit by trial and error, to be finding ways of achieving the seven organizational 'imperatives' identified by Jacques, Blunt and others. ${ }^{9}$ Three characteristics stand out. First is the value system built up in RDRS over 21 years, centred on field orientation, personal integrity and commitment to the poor. Second is the relative freedom which experienced executives have to manage and innovate. Third is RDRS's capacity for selfcriticism and organizational renewal.

NGOs cannot be an alternative to state provision in the longer term. They are not democratically accountable and they are heavily donor-dependent. Many state functions have come about as a result of the need to rationalize and resource the patchwork of services which the voluntary sector tends to create. In countries where the democratic process is recent and fragile, NGOs have a particular responsibility to nurture representative systems, both through broadening their basis in civil society and through direct assistance to the state. Testing and demonstrating organizational forms is one area where NGOs can contribute significantly.

\footnotetext{
${ }^{8}$ RDRS is now reconsidering working through multi-skilled teams as a result of the problems generated by trying to work through multiskilled workers. In this respect, RDRS's unintentional experiment with one feature of post-modern forms (e.g. Clegg 1990:181 et seq.) has not proved wholly positive.

9 The seven imperatives put forward as necessary features of
}

organizational effectiveness are: clearly articulated goals; logical functional alignments; appropriate coordination and control mechanisms; clear role relationships and support for accountability; institutionalized planning; an accepted system for linking performance and reward; and effective leadership. (Blunt 1990, following Jacques 1989). 


\section{REFERENCES}

Ahmed, R. and Hossain, M., 1990, The Developmental Impact of Rural Infrastructure in Bangladesh, International Food Policy Research Institute and Bangladesh Institute of Development Studies

Blunt, P., 1989, 'Strategies for enhancing organizational effectiveness in the Third World'. Public Administration and Development, Vol 10: 299-313

Clegg, S. R., 1990, Modern Organizations - Organization Studies in the Postmodern World, Sage

Franks, T., 1989, Bureaucracy, organization culture and development, Public Administration and Development, Vol 9: 357-368

Government of Bangladesh, 1992, Memorandum for the Bangladesh Aid Group, GOB, Ministry of Planning, Planning Commission, Ministry of Finance Economic Relations Division, April 13

Handy, C., 1990, Inside Organizations, BBC Books

Hofstede, G., 1980, 'Motivation, leadership and organization: do American theories apply abroad? Organizational Dynamics, Summer

Israel, A., 1987, Institutional Development: Incentives to Performance, World Bank

Jacques, E., 1989, Requisite Organization, Cason Hall, Arlington
Jansen, Eirik, 1987, Rural Bangladesh: Competition for Scarce Resources, University Press Ltd, Dhaka

Korten, D., 1980, 'Community organization and rural development strategies: a learning process approach, Public Administration Review, Vol 40 No 5 : $480-511$

Maloney, C., 1988, Behaviour and Poverty in Bangladesh, 2nd edition, University Press Ltd., Dhaka

Orr et al 1991, The Treadle Pump - Manual Irrigation for Small Farmers in Bangladesh, RDRS

Palmer-Jones et al 1991, Report of the Review Mission of the Rangpur Dinajpur Rural Service, RDRS

Peters, T. and Waterman, R., 1982, In Search of Excellence, Lessons from America's Best Run Companies, Harper and Row

RDRS, 1989a, The Comprehensive Project Policy Paper, RDRS, March 1989

-1989b, The Rural Works Project Policy Paper, RDRS, November 1989

-1991, Bangladesh Cyclone Disaster 1991, Relief and Rehabilitation Project Completion Report, RDRS, December 1991

Weber, M., 1947, 'Legitimate authority and bureaucracy', in Weber, The Theory of Social and Economic Organization, translated and edited by A. M. Henderson and T. Parsons Free Press: $328-40$
The IDS mailing list is unique - an invaluable marketing tool for books, catalogues and other promotion material on development economics, politics, rural development, international issues etc.

The list contains approximately 7,000 names and addresses in the field of development studies - in 165 countries throughout the world, including research institutes, university libraries, government departments, voluntary agencies, banks and embassies, academics, civil servants and administrators.

A printout (on adhesive labels) of the IDS mailing list can be purchased for $£ 450$ plus postage. Alternatively, the list may be purchased on disk for multiple use for $£ 1,500$.

Tel: Sarah Haybittle (0273) 606261 (+44 273). 


\section{APPENDIX}

\section{THE ORGANIZATION OF THE RDRS SOCIAL LITERACY PROGRAMME}

The RDRS Social Literacy programme is part of the Comprehensive Project. It is structured round field organizers and informal group of landless families. One field organizer works with about 225 households organized into 15 groups. 46 per cent of the groups are female. Groups are offered education, advice and motivation in five areas: social literacy and organization, agriculture, health, employment generation and women's development. They spend a maximum of five years together to reach a sustainable level of self-reliance. When a group is first formed it meets regularly over many months discussing personal and social issues. Next, a collective saving scheme is started and members may suggest starting to learn to read and write.

Currently, 9,000 people are involved in literacy for one and a half hours a day on an eight-month course. There are two aims of the social literacy work: awareness building and functional skills. The emphasis that project staff give to one or other of these varies and is a focus of debate, as is where to target resources. Some will argue for more resources to go to education work with marriageable girls of 8-13 years old as against a 45 year old male peasant in a literacy class. The organization, in spite of its size, is flexible enough to accommodate such debate.

The literacy course uses three textbooks developed by the Project workers, originally based on the work of BRAC (another large Bangladeshi NGO), together with a detailed teachers' guide. Each book covers 56 lessons structured around picture, word, sign, concept, and number and has skills' acquisition as part of self and group awareness. The literacy courses are seen as 'tasters' for the whole five-year programme. It is agenda-setting literacy. Issues are raised during the sessions - for example 'money lenders', or 'safe water' and people come back to these in later courses on agriculture or health when intensive work on, say, water, food preparation and eyesight will require concepts and skills started during the literacy course.

The tutors are paid volunteers and work with separate men's and women's groups. They come from the community and usually have eight years of schooling. They have a three-week training course and, later, three one-week refresher courses. Tutor payment is relatively good and there is a sliding bonus scheme for successful rates in the external evaluation of the groups. If 80 per cent complete the course, tutors receive double pay. The view taken by the project organizers is that this, together with new learning materials, has sharply improved the quality of the literacy work, although the resource intensiveness of this type of adult education has limited the extent to which this bonus system is applied.

Particular stress is put on evaluation and monitoring. The work of the groups and field workers has been systematized in a monitoring book. This is a large bound volume, one for each field worker. It has 50 items of information on such things as size of holding, access to safe water; number of projects on say goats, cattle; degree of immunization; literacy level. These are aggregated at each of the managerial levels and computerized at the centre. The results are a two-monthly reading of the progress of the project. The monitoring data are discussed in the groups themselves as well as being a means of measuring progress and a system of management control. For example, in 1990 there was an average of 11.02 per cent literacy in the 5,300 groups $(74,000$ people). Some groups showed lower or higher figures in literacy and all levels of the organization would discuss why. Within the literacy class itself, at least 80 per cent of the group have to pass the evaluation stages before the group as a whole moves on. 